\title{
Deadbeat Control of Power Leveling Unit with Bidirectional Buck/boost DC/DC Converter
}

\author{
Shin-ichi Hamasaki, Ryosuke Mukai, Yoshihiro Yano, Mineo Tsuji \\ Division of Electrical Engineering and Computer Science, \\ Nagasaki University, \\ Nagasaki, Japan \\ hama-s@nagasaki-u.ac.jp
}

\begin{abstract}
As a distributed generation system increases, a stable power supply becomes difficult. Thus control of power leveling (PL) unit is required to maintain the balance of power flow for irregular power generation. The unit is required to respond to change of voltage and bidirectional power flow. So the bidirectional buck/boost DC/DC converter is applied for the control of PL unit in this research. The PL unit with Electric double-layer capacitor (EDLC) is able to absorb change of power, and it is examined whether the stable power supply is possible. The output current of PL unit is controlled so as to keep power balance and DC bus voltage. The effectiveness of the deadbeat control for power leveling unit is proved in simulation and experiment.
\end{abstract}

Keywords - power leveling, Bidirectional DC/DC converter, EDLC, deadbeat control

\section{INTRODUCTION}

In recent years, problems of exhaustion of fossil fuel and global warming by $\mathrm{CO}_{2}$ emission being focused, a distributed generator of renewable energy sources such as the photovoltaic (PV) and the wind power generation is attracting attention. New power supply systems, such as a smart grid using distributed generators are expanding[1][4]. Since the output of renewable power sources has fluctuation and instability, however, problems of reverse power flow and voltage optimization occur. Especially, as the renewable power sources increase, change of the power supply becomes intense. Therefore, power fluctuation should be absorbed and the system to equalize the power supply is required as a power leveling. An electric double-layer capacitor (EDLC) has advantages of low inner resistance, large capacity, and long life compared with the secondary battery. EDLC is suitable for absorbing frequent change of power.

In this research, the control system of power leveling (PL) unit combined EDLC with the bidirectional buck/boost DC/DC converter[2] is investigated. The bidirectional buck/boost DC/DC converter can work four-quadrant operation, which is positive and negative voltages and currents. Therefore, the current is able to flow for power charge to EDLC or power supply from EDLC. Even if EDLC is maintaining high voltage or voltage becomes small, it is possible for the PL unit to work adequately. DC bus voltage must be maintained constant, thus the PL unit should operate the leveling quickly for instantaneous fluctuation of power generation. Buck/boost DC/DC Converter applying the deadbeat control[5] based on linearization is proposed to obtain quick response. Effectiveness of the proposed system is verified by simulation and experiment.

\section{Circuit Structure And Control Method}

\section{A. Circuit structure}

Fig. 1 shows a circuit structure of the system in this research. In Fig.1, PL unit consists of Buck/boost DC/DC converter and EDLC. A grid connected inverter is installed between AC bus and DC bus. LC filters are connected to the output terminal of the PL unit and the inverter in order to suppress the switching ripple. The boost chopper is connected to the PV cell for regulation of PV power.

The control is performed by combining two controls, for active and reactive power in $\mathrm{AC}$ side by the inverter, and for input and output power control in DC side by the PL unit. The rate of the output power supplied to the load in AC side can be controlled by the inverter. A current reference $I_{e d}{ }^{*}$ of the PL unit is calculated from the active component current $I_{G d}$ and the output current $I_{p v}$ of a PV cell. Further, in order to keep the DC bus voltage constant, feedback control of the $V_{d c}$ is carried out.

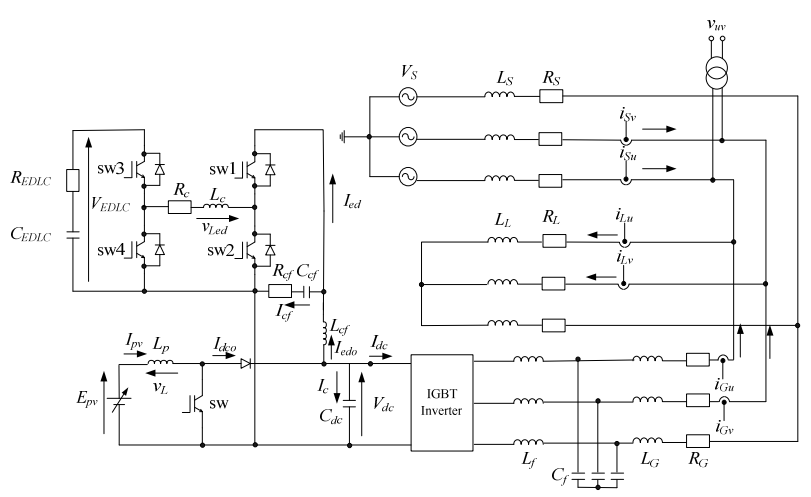

Fig. 1. Circuit structure 


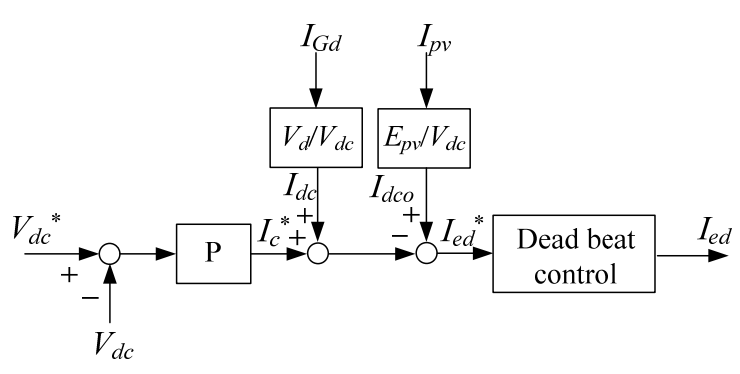

Fig. 2. Block diagram of power leveling unit control

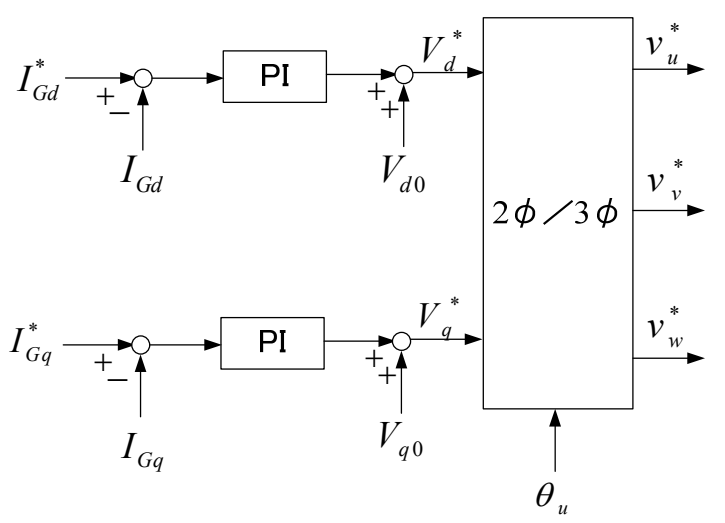

Fig. 3. Block diagram of inverter control.

\section{B. Control of power leveling and inverter}

Fig. 2 shows a block diagram of the PL unit control and Fig. 3 shows a block diagram of the inverter control respectively. Fig.2 is a block diagram in case that the $\mathrm{DC} / \mathrm{DC}$ converter performs in a buck operation as seen from EDLC. Deadbeat control for output current regulator is performed. $I_{e d o}$ is obtained through LPF of $I_{e d}$.

The following equations are derived from Fig.2.

$$
\begin{aligned}
& V_{d c} I_{d c}=V_{d} I_{G d} \\
& E_{p v} I_{p v}=V_{d c} I_{d c o} \\
& I_{e d} \simeq I_{d c o}-I_{c}-I_{d c} \\
& I_{c}^{*}=K_{p c}\left(V_{d c}^{*}-V_{d c}\right)
\end{aligned}
$$

(1)-(3) express a balance of active power and current. LPF is neglected due to few losses in (3). DC bus voltage $V_{d c}$ is regulated by the $\mathrm{P}$ control in (4).

The inverter control is performed by a block diagram in Fig.3. The dq-component converting from the output voltage and currents of the distributed generation system determine the active component and the reactive component. Using them, power flow can be controlled by PI control in (5) and (6). Then $V_{d 0}$ and $V_{q 0}$ are reference voltage calculated from line-to-line voltages on $\mathrm{AC}$ bus.

$$
\begin{aligned}
& V_{d}^{*}=V_{d 0}+K_{p d}\left(I_{G d}^{*}-I_{G d}\right)+K_{i d} \int_{0}^{t}\left(I_{G d}^{*}-I_{G d}\right) d t \\
& V_{q}^{*}=V_{q 0}+K_{p q}\left(I_{G q}^{*}-I_{G q}\right)+K_{i q} \int_{0}^{t}\left(I_{G q}^{*}-I_{G q}\right) d t
\end{aligned}
$$

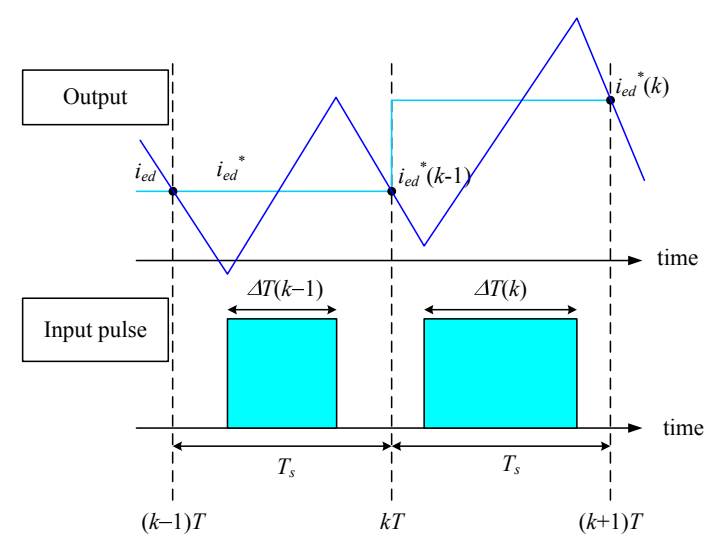

Fig. 4. Principle of deadbeat control

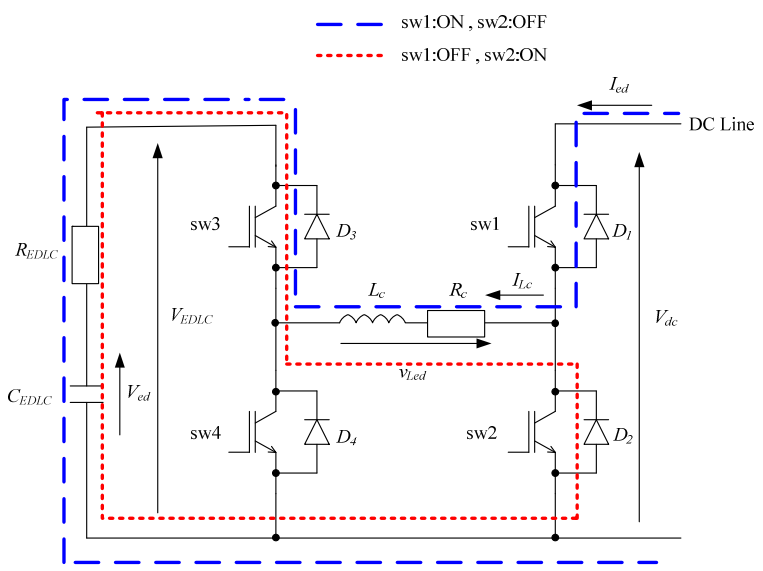

Fig. 5. The operation of boost chopper

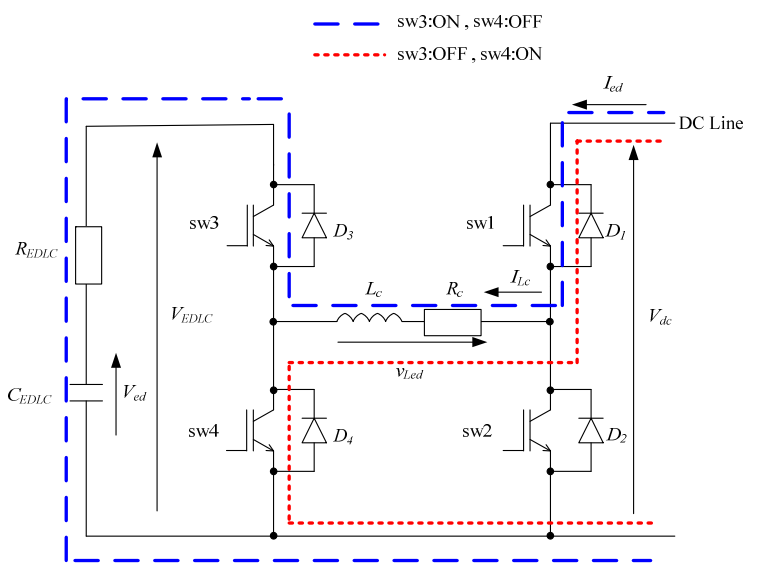

Fig. 6. The operation of buck chopper

\section{Deadbeat control of DC/DC converter}

In order to operate the PL units at high speed, the deadbeat control is applied. Fig. 4 illustrates a principle of the deadbeat control. In this control, it calculates the optimum duty ratio of the PWM at every one period.

Fig.5 shows the operation of boost chopper. The duty ratio of switching is calculated from $I_{L c}{ }^{*}$ and the current $I_{L c}$ of $L_{c}$ when the bidirectional buck/boost DC/DC converter performed a boost operation as seen from EDLC. 
Sw1 and sw2 are alternatively switched according to the calculated duty ratio. Then State equations with respect to on and off operations of sw1 are as follows.

$$
\begin{aligned}
& \mathrm{sw} 1: \mathrm{ON}(\mathrm{sw} 2: \mathrm{OFF}) \\
& \frac{d}{d t}\left[\begin{array}{c}
i_{L c} \\
v_{e d}
\end{array}\right]=\left[\begin{array}{cc}
-\frac{R_{c}+R_{E D L C}}{L_{c}} & -\frac{1}{L_{c}} \\
\frac{1}{C_{E D L C}} & 0
\end{array}\right]\left[\begin{array}{c}
i_{L c} \\
v_{e d}
\end{array}\right]+\left[\begin{array}{c}
\frac{1}{L_{c}} \\
0
\end{array}\right] V_{d c}
\end{aligned}
$$

sw1 : OFF (sw2 : ON)

$$
\frac{d}{d t}\left[\begin{array}{l}
i_{L c} \\
v_{e d}
\end{array}\right]=\left[\begin{array}{cc}
-\frac{R_{E D L C}+R_{c}}{L_{c}} & -\frac{1}{L_{c}} \\
\frac{1}{C_{E D L C}} & 0
\end{array}\right]\left[\begin{array}{l}
i_{L c} \\
v_{e d}
\end{array}\right]+\left[\begin{array}{l}
0 \\
0
\end{array}\right] V_{d c}
$$

The expression of the operation is derived by the statespace averaging method. $d_{1}$ is a duty ratio on the basis of sw1.

$$
\frac{d}{d t}\left[\overline{\frac{i_{L c}}{v_{e d}}}\right]=\left[\begin{array}{cc}
-\frac{R_{E D L C}+R_{c}}{L_{c}} & -\frac{1}{L_{c}} \\
\frac{1}{C_{E D L C}} & 0
\end{array}\right]\left[\begin{array}{c}
\overline{i_{L c}} \\
\overline{v_{e d}}
\end{array}\right]+\left[\begin{array}{c}
\frac{d_{1}}{L_{c}} \\
0
\end{array}\right] \overline{v_{d c}}
$$

Linearization of the equation is performed using minute variations defined by the following equations:

$$
\begin{aligned}
& \bar{v}_{d c} \equiv V_{d c}+\Delta v_{d c}, \bar{v}_{e d} \equiv V_{e d}+\Delta v_{e d}, \bar{i}_{L c} \equiv I_{L c}+\Delta i_{L c}, d_{1} \equiv D+\Delta d_{1} . \\
& \frac{d}{d t}\left[\begin{array}{l}
\Delta i_{L c} \\
\Delta v_{e d}
\end{array}\right]= {\left[\begin{array}{cc}
-\frac{R_{E D L C}}{L_{c}} & -\frac{1}{L_{c}} \\
\frac{1}{C_{E D L C}} & 0
\end{array}\right]\left[\begin{array}{c}
\Delta i_{L c} \\
\Delta v_{e d}
\end{array}\right] } \\
&+ {\left[\begin{array}{c}
\frac{V_{d c}}{L_{c}} \\
0
\end{array}\right] \Delta d_{1}+\left[\begin{array}{c}
\frac{D_{1}}{L_{c}} \\
0
\end{array}\right] \Delta v_{d c} }
\end{aligned}
$$

Replacing $\Delta i_{L C}=\Delta i_{L c}{ }^{*}, \Delta d_{1}(k)$ is obtained by backward difference method of $z$-transform from (10).

$$
\Delta d_{1}(k)=\frac{\Delta i_{L c}^{*}(k)-k_{2} \Delta i_{L c}(k-1)-k_{3} \Delta v_{e d}(k-1)-k_{4} \Delta v_{d c}(k)}{k_{1}}
$$

,where $k_{1}, k_{2}, k_{3}$ and $k_{4}$ are constants to be determined by circuit parameters. The duty ratio $D_{l}(k)$ at sampling period $k T$ is obtained by (12).

$$
D_{1}(k)=D_{1}(k-1)+\Delta d_{1}(k)
$$

It is possible to determine the optimal PWM duty ratio $D_{1}(k)$ by (12). And the output current $I_{L c}$ can follow the reference value $I_{L c}{ }^{*}$ with one sample delay.

Fig.6 shows the operation of buck chopper as seen from EDLC. Sw3 and sw4 are alternatively switched according to the calculated duty ratio. Then State equations with respect to on and off operations of sw3 are as follows. sw3 : ON (sw4 : OFF)

$$
\frac{d}{d t}\left[\begin{array}{c}
i_{L c} \\
v_{e d}
\end{array}\right]=\left[\begin{array}{cc}
-\frac{R_{c}+R_{E D L C}}{L_{c}} & -\frac{1}{L_{c}} \\
\frac{1}{C_{E D L C}} & 0
\end{array}\right]\left[\begin{array}{c}
i_{L c} \\
v_{e d}
\end{array}\right]+\left[\begin{array}{c}
\frac{1}{L_{c}} \\
0
\end{array}\right] V_{d c}
$$

sw3 : OFF (sw4 : ON)

$$
\frac{d}{d t}\left[\begin{array}{c}
i_{L c} \\
v_{e d}
\end{array}\right]=\left[\begin{array}{cc}
-\frac{R_{c}}{L_{c}} & 0 \\
0 & 0
\end{array}\right]\left[\begin{array}{c}
i_{L c} \\
v_{e d}
\end{array}\right]+\left[\begin{array}{c}
\frac{1}{L_{c}} \\
0
\end{array}\right] V_{d c}
$$

The expression of the operation is derived by the statespace averaging method. $d_{2}$ is a duty ratio on the basis of sw3.

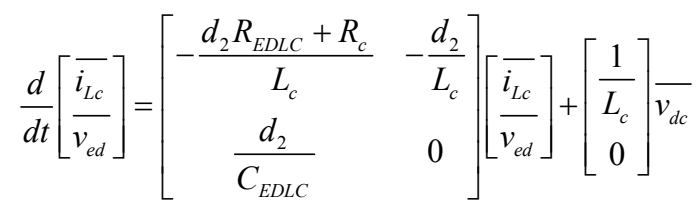

Then the equation is performed by the linearization using minute variations the same as the boost operation in (9) and (10).

$$
\begin{aligned}
\frac{d}{d t}\left[\begin{array}{c}
\Delta i_{L c} \\
\Delta v_{e d}
\end{array}\right] & =\left[\begin{array}{cc}
-\frac{R_{c}+D_{2} R_{E D L C}}{L_{c}} & -\frac{D_{2}}{L_{c}} \\
\frac{D_{2}}{C_{E D L C}} & 0
\end{array}\right]\left[\begin{array}{c}
\Delta i_{L c} \\
\Delta v_{e d}
\end{array}\right] \\
& +\left[\begin{array}{c}
\frac{R_{E D L C} I_{L c}-V_{e d}}{L_{c}} \\
\frac{I_{e d}}{C_{E D L C}}
\end{array}\right] \Delta d_{2}+\left[\begin{array}{c}
\frac{1}{L_{c}} \\
0
\end{array}\right] \Delta v_{d c}
\end{aligned}
$$

$\Delta d_{2}(k)$ is calculated by backward difference method of $z$-transform from (16).

$$
\Delta d(k)=\frac{\Delta i_{L c}^{*}(k)-m_{2} \Delta i_{L c}(k-1)-m_{3} \Delta v_{e d}(k-1)-m_{4} \Delta v_{d c}(k)}{m_{1}}
$$

,where $m_{1}, m_{2}, m_{3}$ and $m_{4}$ are constants to be determined by circuit parameters. The Duty ratio $D_{2}(k)$ is obtained by (18).

$$
D_{2}(k)=D_{2}(k-1)+\Delta d_{2}(k)
$$

\section{SIMULATION}

Simulation is performed to verify the proposed control method by using the circuit in Fig.1. Table I shows the parameters of the circuit.

Figs. 7 and 8 show simulation results in the case of boost and buck operation respectively. The PV gives practical output with fluctuation using random function. 


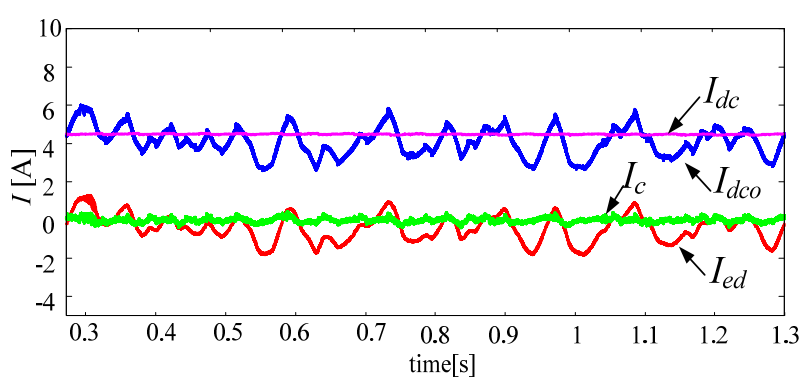

(a) Currents on DC bus

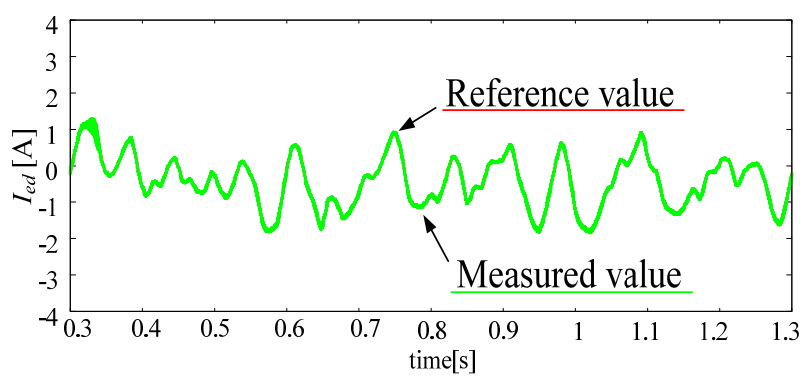

(b) Output current of the PL unit

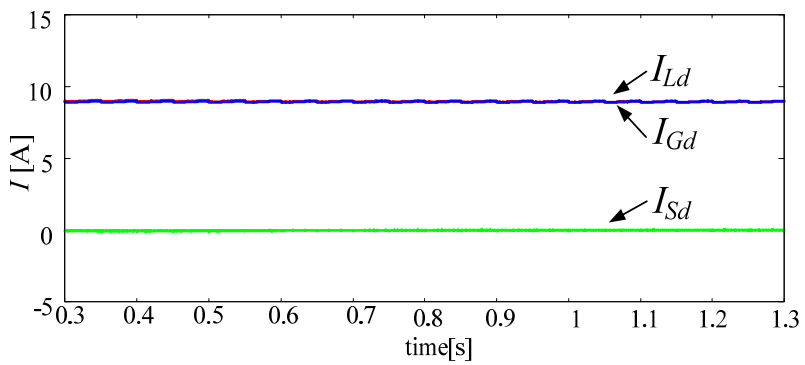

(c) Active current of inverter on $\mathrm{AC}$ side

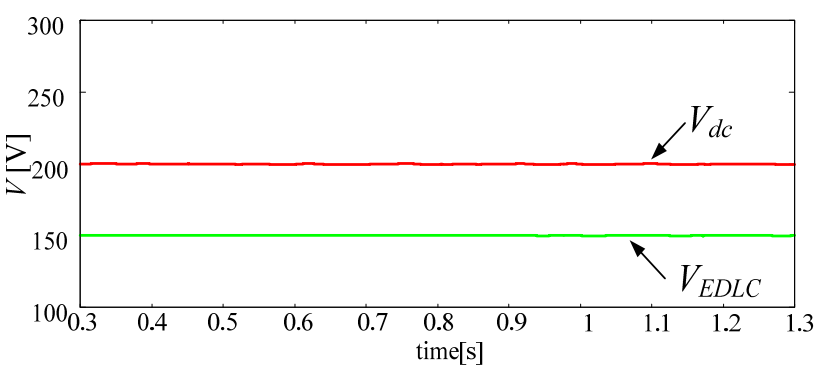

(d) Voltages in DC side

Fig. 7. Results in case of boost chopper operation

TABLE I

PARAMETERS OF THE CIRCUIT

\begin{tabular}{|c|c|c|c|}
\hline Line voltage & $100 \mathrm{~V}$ & Frequency & $60 \mathrm{~Hz}$ \\
\hline$R_{S}$ & $0.25 \Omega$ & $L_{S}$ & $218 \mu \mathrm{H}$ \\
\hline$R_{G}$ & $0.15 \Omega$ & $L_{G}$ & $131 \mu \mathrm{H}$ \\
\hline$R_{L}$ & $10.00 \Omega$ & $L_{L}$ & $8.72 \mathrm{mH}$ \\
\hline$L_{f}$ & $0.01 \mathrm{H}$ & $C_{f}$ & $5.00 \mu \mathrm{F}$ \\
\hline$V_{d c}$ & $200 \mathrm{~V}$ & $C_{d c}$ & $5000 \mu \mathrm{F}$ \\
\hline$L_{c}$ & $10.0 \mathrm{mH}$ & $R_{c}$ & $1.5 \mathrm{~m} \Omega$ \\
\hline$R_{E D L C}$ & $0.027 \Omega$ & $C_{E D L C}$ & $10.0 \mathrm{~F}$ \\
\hline$L_{p}$ & $10.0 \mathrm{mH}$ & $E_{p v}$ & $80.0 \mathrm{~V}$ \\
\hline$C_{c f}$ & $30.0 \mu \mathrm{F}$ & $L_{c f}$ & $1.5 \mathrm{mH}$ \\
\hline
\end{tabular}

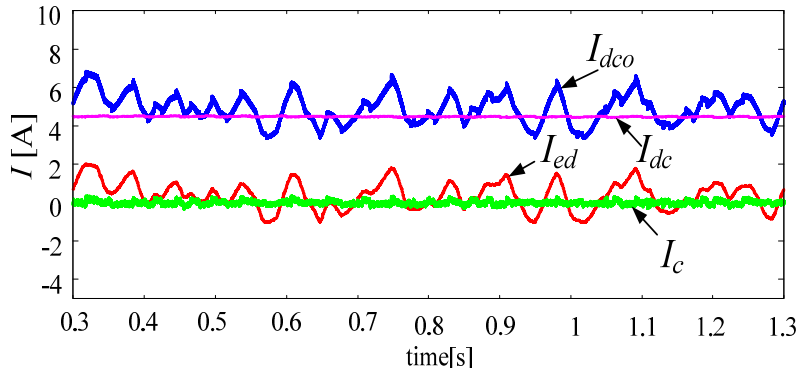

(a) Currents on DC bus

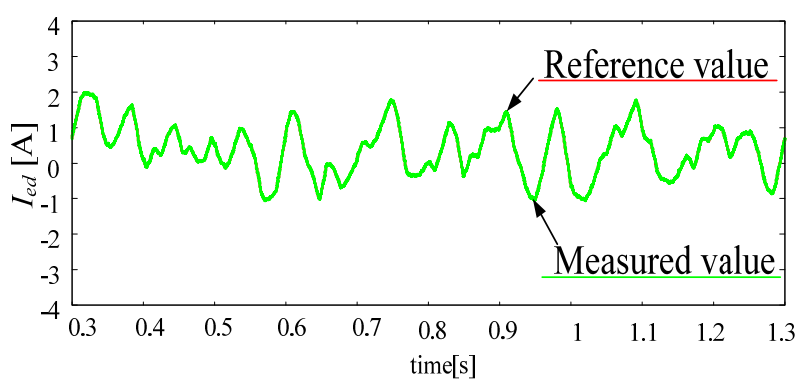

(b) Output current of the PL unit

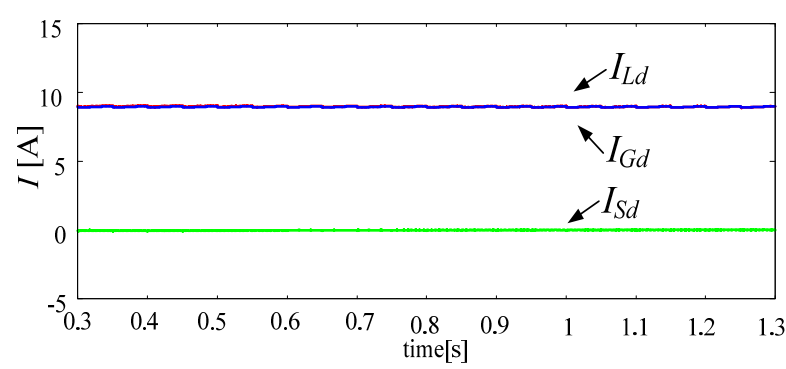

(c) Active current of inverter on AC side

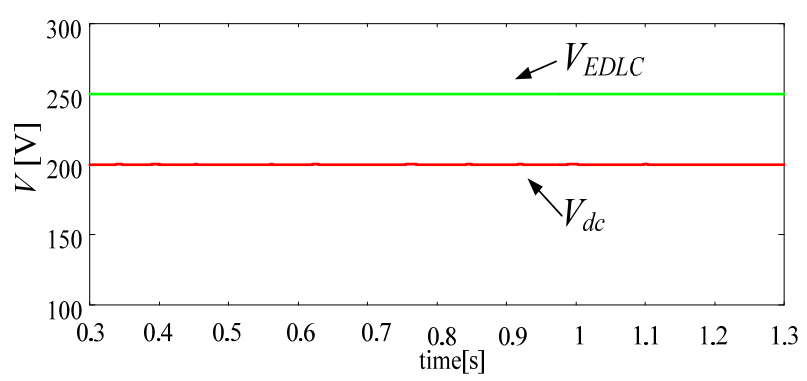

(d) Voltages in DC side

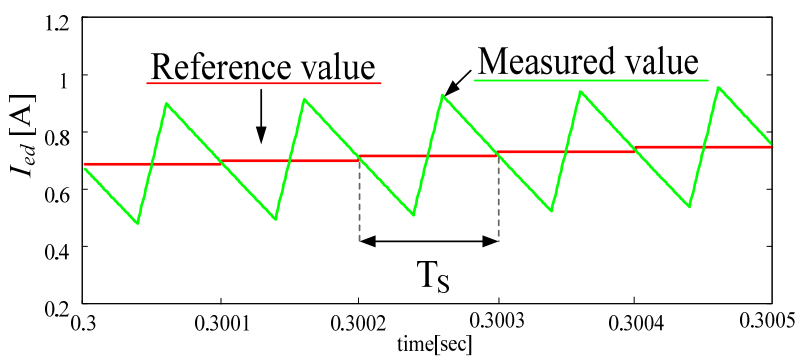

(e) Focus of output current of the PL unit

Fig. 8. Results in case of buck chopper operation

Fig.7 shows results in case that the bidirectional chopper works as a boost chopper $\left(V_{E D L C}<V_{d c}\right)$. It is controlled in order to keep balance of the charge and discharge of EDLC against the change of PV output in Fig.7(a) and (b). In Fig.7(b), the positive current means charge to 


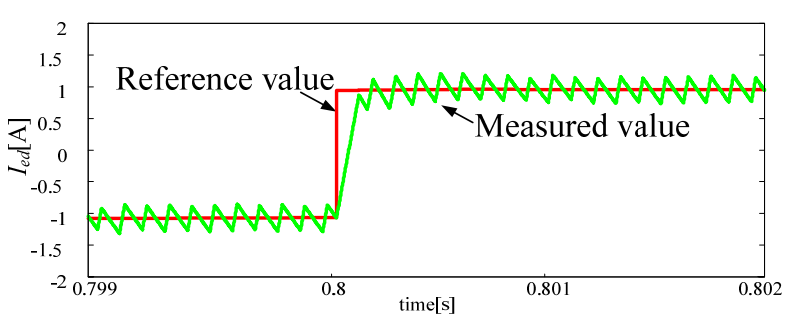

(a) Deadbeat control

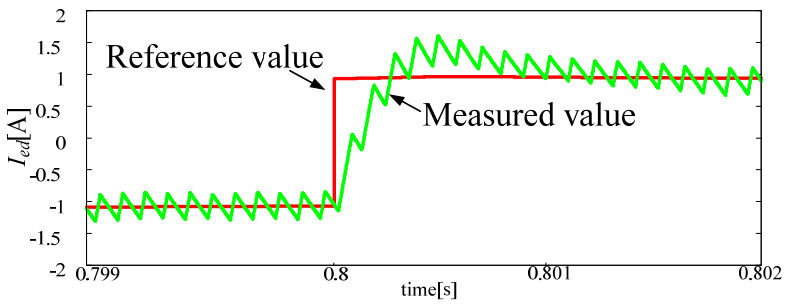

(b) PI control.

Fig. 9. Results of comparison in case of buck chopper operation

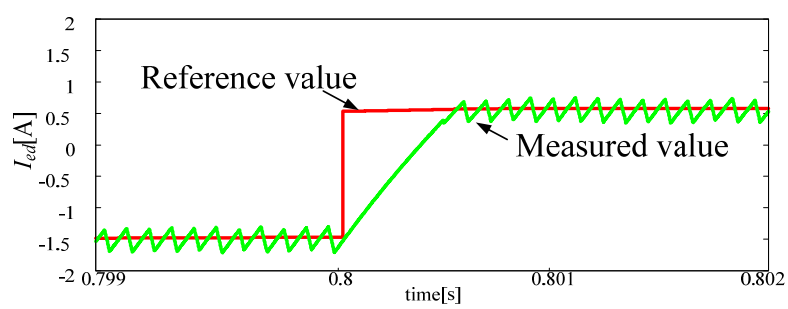

(a) Deadbeat control

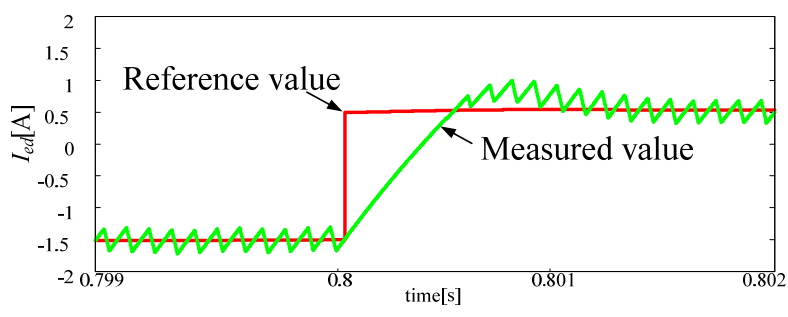

(b) PI control

Fig. 10. Results of comparison in case of boost chopper operation

EDLC and the negative one means power supply to the DC bus, respectively. And output current can follow to the reference by the deadbeat control. Fig.7(c) shows results with the power control based on the main AC bus. $I_{S d}$ becomes almost zero. $I_{G d}$ and $I_{L d}$ are the same value. This means that all the power is supplied from only distributed generation system and the main system does not send out the power. In Fig.7(d), DC bus voltage keeps constant, and the bidirectional buck/boost DC/DC converter is operating properly as a boost chopper.

Fig. 8 shows results in case that the bidirectional chopper works as a buck chopper $\left(V_{E D L C}>V_{d c}\right)$. It is controlled in order to keep balance of the charge and power supply of EDLC against change of PV output in Fig.8 (a) and (b). In Fig.8(b), the output current follows to the reference and can compensate the fluctuation of PV output properly. The power supplied to AC side keeps constant in Fig.8 (c). In Fig.8(d), DC bus voltage keeps constant, and the bidirectional buck/boost DC/DC converter is operating properly as a boost chopper. Fig.8(e) shows an enlarged figure of Fig.8(b). We can see that the measured value follows to the reference value every one sample and is able to confirm quick response for the operation of the PL unit.

Fig.9 shows results of comparison with the deadbeat control and conventional PU control in case of buck chopper operation. The gain design of PI control is selected for fast response and small overshoot. In Fig.9(b), settling time is almost $0.002 \mathrm{~s}$ and overshoot is $0.5 \mathrm{~A}$. On the other hand, settling time of deadbeat control is shorter than the PI control and overshoot is nothing in Fig.9(a). Fig.10 shows results of comparison in case of boost chopper operation. Settling time of the deadbeat control is shorter than the PI control and overshoot is nothing the same as Fig.9.

\section{EXPERIMENT}

In order to verify the proposed PL unit operation, Experimental system for DC bus is constructed as shown in Fig.11. The PL unit consists of IGBT (Mitsubishi Elec. : PM50CL1A060) and EDLC (Shizuki Elec. : FML-3A). The PV is simulated by a power AMP. An electric load is used for a constant current consumption.

All the controls are executed by the DSP (TI : TMS320C33-150MHz). PWM switching frequency is 10 $\mathrm{kHz}$ and sampling period of DSP is $100 \mu \mathrm{s}$ in the experiment.

Figs.12-14 show the experimental result in three situations.

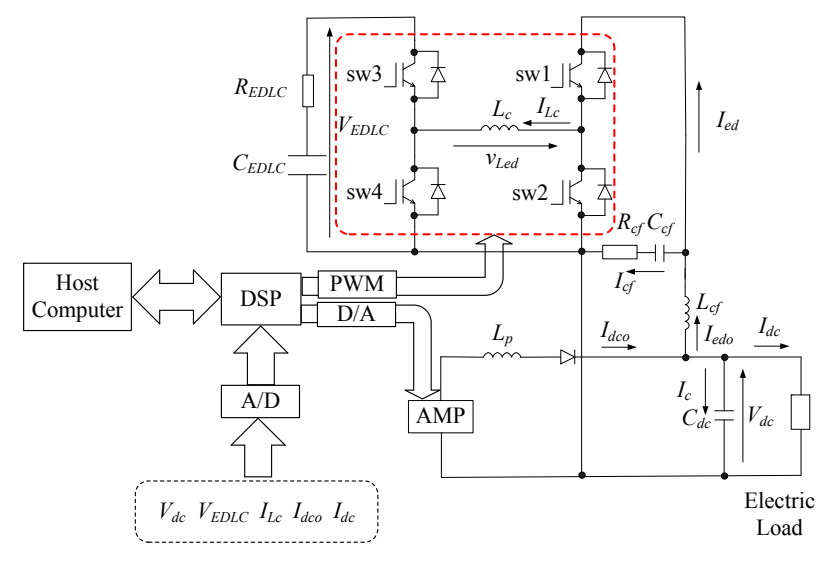

Fig. 11. Configuration of experimental system

TABLE II

PARAMETERS OF EXPERIMENTAL CIRCUIT

\begin{tabular}{|c|c|c|c|}
\hline$L_{c}$ & $5.0 \mathrm{mH}$ & $C_{d c}$ & $10.0 \mathrm{mF}$ \\
\hline$C_{E D L C}$ & $60.0 \mathrm{~F}$ & $R_{E D L C}$ & $0.027 \Omega$ \\
\hline$C_{c f}$ & $30.0 \mu \mathrm{F}$ & $L_{c f}$ & $1.5 \mathrm{mH}$ \\
\hline$L_{p}$ & $0.2 \mathrm{mH}$ & $V_{d c}{ }^{*}$ & $25.0 \mathrm{~V}$ \\
\hline
\end{tabular}



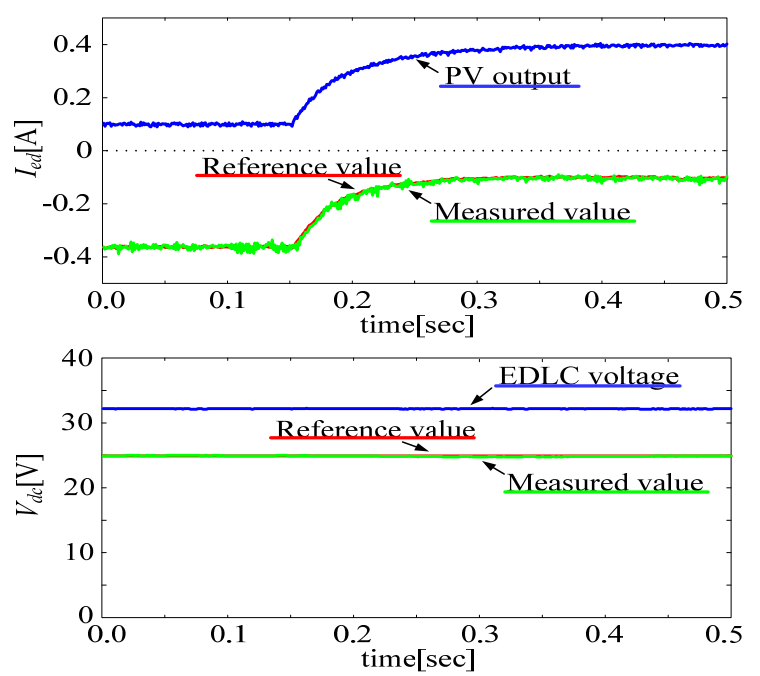

Fig. 12. Experimental result (operation of buck and supply)
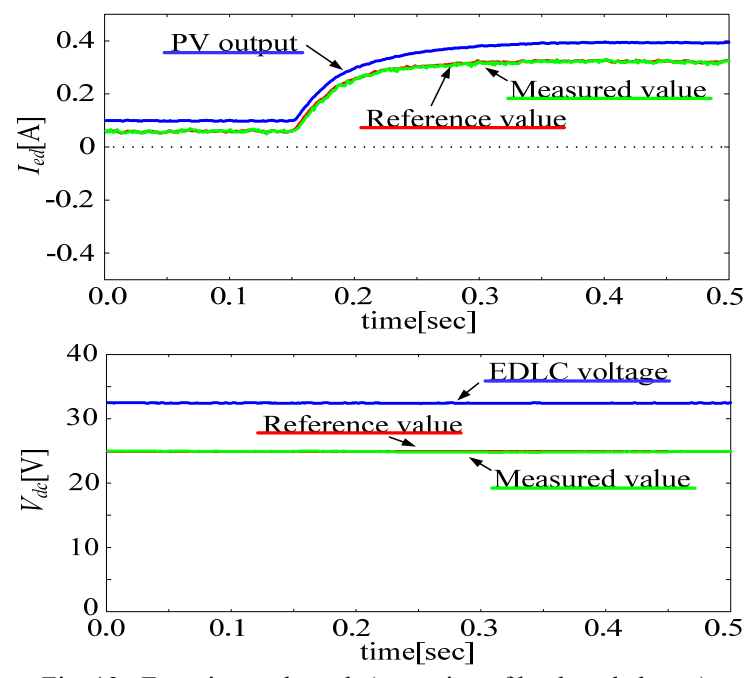

Fig. 13. Experimental result (operation of buck and charge)

Figs. 12 and 13 are cases of buck operation $\left(V_{E D L C}>V_{d c}\right)$ for power supply from EDLC $\left(I_{e d}<0\right)$ and charge to EDLC $\left(I_{e d}>0\right)$, respectively. Voltage of EDLC is $32 \mathrm{~V}$ at the start. The simulated PV output increases at $t=0.15 \mathrm{~s}$. Output current of PL unit precisely follows to the reference by the deadbeat control. As a result, DC bus voltage keeps constant by the voltage control correctly.

Fig. 14 is a case that output current changes from discharge to charge. In this case, operation of PL unit is good the same as Figs.12 and 13. Fig.15 shows an example of current control by conventional PI control for comparison. An error occurs at around 0A due to discontinuous of current in a reactor. However, the proposed method is able to control the current without error.

\section{CONCLUSIONS}

In this study, the deadbeat control of PL unit with EDLC using the bidirectional buck/boost DC/DC converter is proposed. The effectiveness of the deadbeat control was confirmed by the simulation and the experiment in various conditions such as charge or discharge of
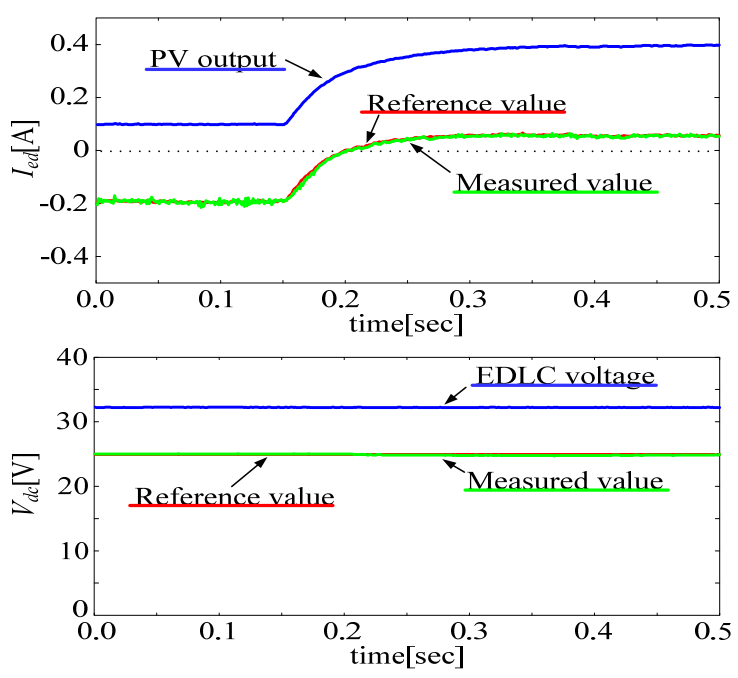

Fig. 14. Experimental result (change supply to charge)

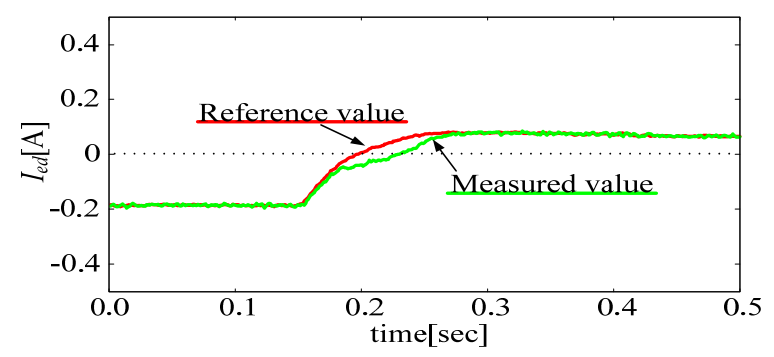

Fig. 15. Experimental result by PI control

EDLC, PV power fluctuation and so on. The output current followed the reference value every one sample and is able to confirm the quick response without error by the proposed method.

\section{REFERENCES}

[1] Y. Ito, Z. Yang, and H. Akagi, "A Control Method of a SmallScale DC Power System Including Distributed Generators", IEEJ Trans. IA, Vol.126, No.9, 2006

[2] S. Funabiki, M. Yamamoto : "Estimation of Bidirectional Buck/boost DC/DC Converters with Electric Double-Layer Capacitors for Energy Storage Systems", IEEJ Trans. IA, Vol.129, No.6, pp.658-663, 2009

[3] H. Kakigano, T. Ise, et al. : "DC Voltage Control of the DC Micro-Grid for Super High Quality Electric Power Distribution" (in Japanese), JIEE Trans. on Industrial Application, vol. 127, No. 8, pp.890-897, 2007

[4] K. Yukita, Y. Shimizu, Y. Goto, et al., "Study of AC/DC Power Supply System with DGs using Parallel Processing Method", The 2010 International Power Electronics Conference (IPEC), pp.722-725, 2010

[5] S. Hamasaki and A. Kawamura, "Improvement of Current Regulation of Line-Current-Detection-type Active Filter based on Deadbeat Control", IEEE Trans. on Industrial Application, Vol.39, No.2, pp.536-541, 2003

[6] S. Hamasaki, M. Tsuji, E. Yamada : "A Study on Power Flow Control for Distributed Generator with EDLC", SYMPOSIUM ON POWER ELECTRONICS, ELECTRICAL DRIVES, AUTOMATION AND MOTION (SPEEDAM), Vol.1, pp.15021507,2010

[7] S. Hamasaki, R. Mukai, M. Tsuji : "Control of Power Leveling Unit with Super Capacitor using Bidirectional Buck/boost DC/DC Converter", ICRERA2013, Vol.1, 2013 